\title{
ENFORCEMENT PROBLEMS IN ROSCAS: EVIDENCE FROM BENIN
}

\section{Accepted at The European Journal of Development Research}

\author{
Kyle McNabb, UNU Wider \\ Philippe LeMay-Boucher, Heriot-Watt University \\ Jacopo Bonan, Politecnico di Milano
}

\begin{abstract}
Using data from a unique field survey in urban Benin, we investigate the sustainability of Rotating Savings and Credit Associations (ROSCAs) over time. We test the theories from the relevant literature that suggest ROSCAs can be designed in a manner that minimizes the likelihood of enforcement problems occurring. The data paints a picture of inherent instability: over a two-year period, 1 in 3 groups experienced enforcement problems; two thirds of which collapsed. Results highlight the importance of the order of pot allocation, ruling structure, social connectedness in minimizing the risk of enforcement problems occurring. Repeated interactions amongst members can also enhance sustainability over time.
\end{abstract}

Keywords: Economics; ROSCAs; Informal Finance; Benin; Africa; Social Capital

\section{INTRODUCTION}

Whilst a 'deeply entrenched tradition' of saving exists in Benin, the majority of deposits are held informally, for example in rotating savings and credit associations (ROSCAs) or with an itinerant banker (Helms et al., 2005). An estimated 81-89 percent of Beninese individuals were using ROSCAs in the year 2000, whilst some estimates suggest that just 10 percent of all deposits at this time were held in the formal banking system (Gracia et al., 2005). 
Informal financial institutions are particularly widespread where individuals have limited access to formal credit or savings markets [1]. Indeed, despite the proliferation of alternatives such as microfinance institutions (MFIs) or mobile banking, many in developing countries still choose to keep some or all of their savings in informal financial institutions such as ROSCAs [2]. A ROSCA consists of a group of individuals who gather on a regular basis for a cycle of meetings. At each meeting, all members contribute a fixed sum of money to a common pot which is allocated to one of them. The recipient is then excluded from the reception of the collective savings in subsequent meetings but continues to contribute to the pot for the rest of the cycle. This process repeats until each member has received the pot, marking the end of a cycle. The ROSCA may then begin another cycle or decide to disband. Beyond this basic framework, ROSCAs vary across many dimensions such as size, frequency of meetings, the order in which the pot is allocated and ruling structure.

Yet, the sustainability of ROSCAs has puzzled economists; the incentives for the self-seeking individual to renege on payments after she has received the collective savings often outweigh those to remain loyal to the arrangement. Furthermore, their use as savings devices presents a number of disadvantages compared to, for example, saving in autarky; they require a commitment to an inflexible savings pattern, do not provide interest and cannot be legally enforced. Numerous studies have shed light on the importance of social connectedness between members, who front a kind of social collateral (Besley et al., 1993) to their fellow members as security. The threat of social sanctions (i.e. obtaining a reputation for being unreliable, or exclusion from the group and future groups in the region) brings with it a large cost to default and thus an incentive to remain loyal to one's peers. At the same time, many ROSCAs also serve a social purpose. Members may meet with others on a regular basis, to for example share meals, organise celebrations together on special occasions (end of year or cycle) or share contacts and potential business opportunities. 
Studies such as Anderson et al. (2009) or Besley et al. (1993) have analysed the question of ROSCA sustainability at the individual level and the conditions (or ROSCA design) under which default is likely to occur. The motivations and findings of these studies are detailed below in section 3. However, some of their predictions have not yet been tested empirically. All existing field surveys of ROSCAs examine membership or group characteristics at one point in time. By definition, any groups that had collapsed due to default or enforcement problems would have been omitted from these studies. As a result, we know relatively little about the lifespan of ROSCAs and their ability to deal with enforcement problems. However, losing one's savings if another member defaults poses a potentially serious negative income shock to ROSCA members and as such a knowledge of the optimal structure or sociocultural makeup of groups is important.

This study presents new evidence into the sustainability of ROSCAs over time, a question that has received only scant attention in the literature. We use a unique dataset of urban ROSCAs collected in Cotonou, Benin. After an initial field survey in 2004 where information was gathered on the characteristics of the membership and the groups themselves, we returned in 2006 to assess the same groups. Thus, our analysis is at the group level. Handa and Kirton (1999), Dagnelie (2008) and Bauchet and Larsen (2018) are the only other studies to our knowledge that have empirically considered the sustainability of ROSCAs [3]. Where relevant below, we compare and contrast our findings with these studies. Our data paints a picture of inherent instability amongst Beninese ROSCAs - in the two years between the surveys, around one in three groups had experienced enforcement problems; the majority of these collapsed entirely as a result. This is in contrast to Bauchet and Larsen (2018), who found that just 10 percent of their sample of 60 Taiwanese ROSCASs experienced repayment issues. Enforcement problems, in our context, are defined as a scenario where a member has missed at least one payment either before or after pot reception, though it also includes outright default. Using data from the 2004 wave of the survey, 
we seek to assess how various group characteristics can influence the incentives for members to default or miss payments- and thus on the likelihood that the group as a whole experienced an enforcement problem- in the following two years.

The empirical analysis tests the main theories outlined in the theoretical literature with regards to the effect of various group characteristics on the likelihood that a group experiences enforcement problems. The results of a Probit regression offer support for the theory that ROSCA design matters for minimising the likelihood of experiencing enforcement problems. As we detail below, our model lacks a number of variables linked to the composition (membership) of the group and thus our estimated coefficients should only confidently be interpreted as correlations. We find that groups that fix the allocation of funds based on members' need, as opposed to a random draw, were less likely to experience problems, as were groups with written rules and those that met less frequently. The results also suggest that those groups led by a sole president, as opposed to a committee of members, were also significantly less likely to experience problems. A number of proxies are considered in order to capture the level of social capital existing amongst members and results support the notion that social ties are key to enforcement. In particular, those groups started amongst family members appeared less likely to have experienced enforcement problems than those started amongst colleagues or friends. A further way in which the risk of enforcement problems can be minimised is through the screening of new members. Thus, we draw parallels to, e.g. Ghatak (1999), who showed that higher repayment rates might be possible where group-lenders were able to choose new borrowers. The screening role might fall upon the president or ruling committee (or the group as a whole) and a variety of different means, such as surveying new members, can be used. Our results suggest that those groups which stipulated that new members must be known to at least one current member were less likely to have experienced enforcement problems. We also find evidence that as groups get older or more experienced, the effect of the aforementioned features on the likelihood of experiencing enforcement problems 
diminishes, suggesting that repeated interactions in the ROSCA setting can help to enforce the bonds of reciprocity amongst members. It is important to note that

The remainder of this paper is organised as follows. Section 2 introduces our Beninese sample, providing descriptive statistics of the key variables that are tested in the empirical section. In section 3 , the theory and intuitions shaping the incentives for a member to remain true to the ROSCA are discussed in detail. We form a number of conjectures that are tested empirically in section 4. Section 5 considers some extensions and section 6 concludes.

\section{THE BENINESE CONTEXT AND DESCRIPTIVE STATISTICS}

The data for this study was collected during two waves of household surveys in 2004 and 2006 in Cotonou (Benin) [4]. Surveys were carried out in two of the poorest areas of the city, Vossa and Enagnon. No banks, NGO's or other formal institutions offered saving facilities in these regions at the time. From our initial pilot surveys, these areas were known to be rich in ROSCAs [5]. 497 households were randomly selected in the first wave of the survey. Within these, information on 182 active ROSCAs was uncovered (when an individual responded that he or she was a ROSCA member, a questionnaire on the characteristics of the group was administered). Whilst the enumerators made every effort to track down members of all 182 groups in the second wave of the survey, it was not always possible. In 2006, we surveyed 386 households of the original 497 (which represents an attrition rate of 22.3\%). Many had left their family home or the area entirely [6]. In this sample of 386 households, we collected data for 97 of the original 182 ROSCAs. That represents an attrition rate of $46.7 \%$. A further reason that can help explain the high level of group attrition is that even when ROSCA members were successfully interviewed in both waves, some had left their ROSCA at the end of a cycle during the two-year period, 
without the group experiencing enforcement problems. For some, when we surveyed them again in 2006, it was thus not possible to infer whether that ROSCA was still active.

However, aside from the reduced sample size, this only becomes an issue if attrition is systematic along some of the variables of interest. A regression where the dependent variable was an indicator of attrition is shown in Appendix B. This highlights that none of the key variables considered in the main analysis below were significant explanatory factors of whether a group was surveyed again or not. This indicates that the likelihood of an individual being surveyed in the second round is unrelated to any of the ROSCA characteristics.

Our empirical analysis considers the likelihood of a ROSCA experiencing enforcement problems during the 2004-06 period, based on its initial characteristics measured in 2004 [7]. Table 1 presents summary statistics of the key characteristics of the ROSCAs in our sample. It also includes a test for equivalence of means between groups that did not experience enforcement problems between 2004 and 2006 (64) and those that did (33). 'Enforcement problems', in this study, denotes a case where a group had experienced at least one case of non-payment between 2004 and 2006. It could be argued that such a definition sets a high bar for functionality, as it applies even if only one member missed one payment over the last two years. Compared to a typical MFI providing loans, such levels of default are deemed acceptable. However, as our data show, in the case of ROSCAs, the margin of error is narrower: a single default can often impact on the survival of the group. Whereas MFIs can survive with rates of repayment around 90-95 per cent, out of the 33 ROSCAs we observed that had experienced enforcement problems, 23 collapsed as a direct consequence. Thus, we consider our definition of enforcement problems an appropriate barometer of functionality. Furthermore, it is comparable to the definition used the theoretical study of ROSCA sustainability by Anderson et al., (2009) [8]. 
The member who answered our questions about a specific ROSCA in 2004 was surveyed again in 2006 about that same group. 23 of the groups surveyed again in 2006 had ceased to exist due to non-payment of contributions. For these groups, we do not have information on the characteristics of these ROSCAs either in 2006 or at the moment just before they ceased their activities (between 2004 and 2006). So, for these groups we do not have panel data. Whilst for the 74 other groups we do have panel data for the variables shown in table 1 for 2004 and 2006, the missing information for the groups that ceased to exist means that we cannot check how rule changes impact group sustainability and use variations to identify their effects. Thus, our estimation models investigating the likelihood of a ROSCA experiencing enforcement problems during the 2004-06 period is based on the initial characteristics measured in 2004 and, as such, on cross-sectional data.

The average ROSCA comprised around 33 members, although this ranged from 4 to 175 . In 2004, each group had completed an average of 8 cycles, although at the time of the survey, some had not yet completed their first. It appears that the subset of groups that experienced enforcement problems were on average significantly smaller and younger. A key variable that could affect the incentives to default is the order in which the pot is allocated. Broadly speaking, this is done according to a fixed order (always fixed at the start of a cycle), random draw (either at the start of a cycle or at each meeting), or to the highest bidder. $32 \%$ of our sample had a fixed order, with the remainder allocating the pot according to a random draw; no 'bidding' ROSCAs were observed in Cotonou. Of those groups allocating the pot according to a fixed process, this was determined by the i) seniority of members (5 groups); ii) members need of the money (13); iii) regularity of attendance (6); iv) appropriateness of a request (4). The variable 'Need' is a dummy taking the value one if the pot was allocated according to criteria (ii). This might represent a situation where a member requests a specific rank in the cycle in order to cover some unforeseen expense, or it might be the case that members prefer to receive the funds at a certain date to cover 
regular lumpy expenses such as purchasing stock for a business or paying school fees. The variable 'Other fixed' accounts for those groups setting the order of pot reception according to one of the other criteria listed.

A lone president, as opposed to a ruling committee, ran $30 \%$ of groups. The average size of a group run by a president (22) was significantly smaller than that overseen by a committee (38). This might well be taken as a reflection of the greater workload for a sole president in larger groups.

A significantly larger proportion of groups that did not experience enforcement problems had written rules (67\%), compared to those that did (46\%); around $60 \%$ of the full sample had rules. ROSCAs that had experienced problems (and continued to exist) pre-2004 appear much more likely to see a recurrence between 2004 and 2006. Almost half (49\%; 16 of 33) of the groups experiencing problems between 2004 and 2006 had also done so in the past. Of those 16 experiencing a recurrence, 7 were able to overcome them and survive. However, of the 17 groups experiencing problems between 2004 and 2006 for the first time, only 3 were able to survive. This suggests that for some groups, enforcement problems are a fairly regular occurrence, but that they have devised means to cope with it.

Despite the substantial threat of social sanctions on members who miss payments, many groups also imposed more traditional forms of punishment on delinquents. A number of sanctions were employed; the variable 'More severe sanctions on delinquent member' represents the fraction of groups imposing at least one of those sanctions deemed to be more severe. These included '[the delinquent] receives a less favorable rank in the next cycle', '[the delinquent] is penalized at the breakdown of cash', '[the delinquent] receives his own contributions back but does not receive the pot at his turn', 'a fine must be paid,' '[the delinquent] does not receive the pot at his turn' or 'property seized'. [9] Conversely, those we classify as less severe are 'no penalty', 'the person 
receiving the pot in this period need not contribute to the pot when it is the delinquent's turn to receive the pot' and [the delinquent] is given a period in which to pay.' The majority of groups imposed 'more severe sanctions' upon a delinquent. In terms of regularity of meeting, 35\% of groups met once per week, $37 \%$ met monthly, one met daily whilst others met every two weeks $(8 \%)$, every ten days $(3 \%)$, or 2-3 times per week $(16 \%)$.

Whilst inherently difficult to measure, our study uses a number of proxies to capture the level of social capital that exists between members. Notably, we asked groups about the pre-existing social connections, or similarities that existed at inception - we see that $43 \%$ were started amongst friends; around $24 \%$ were exclusively for members of the same ethnic group (denoted by the variable 'Single Ethnicity') and around 40\% of groups were restricted to either only males or only females (denoted by the variables 'Only men' and 'Only Women'). $61 \%$ of those groups that experienced enforcement problems between 2004 and 2006 were started amongst friends, compared to only $34 \%$ of those not experiencing problems. This difference is significant at the $5 \%$ level. A majority of groups surveyed new members or stipulated that entrants must be known to the current membership (79\% and $61 \%$ respectively; denoted by the variables 'Survey on new members' and 'New members must be known'); just under half of the sample imposed both restrictions and only $6 \%$ imposed neither restriction. The president or ruling committee were entrusted with the decision over whether to admit new members in $65 \%$ of groups in our sample (denoted by the variable 'President/Committee decides'), with the remainder deciding as a whole. The variable 'Other Conditions' signifies that around $78 \%$ of groups imposed other constraints $[10]$.

\section{INSTITUTIONAL DESIGN AND SOCIAL CAPITAL}


In this section, we form conjectures that will be tested in section 4 using the data described above. In the absence of a well-designed incentive mechanism, there will be a temptation for the utility maximising ROSCA member to take the collective savings and default on further payments. Besley et al. (1993) offers a basic framework which argues that the incentives to default can be affected by both the costs and benefits of doing so. The latter can be influenced by the size of the pot, group size or an individuals' rank, which itself is influenced by the means by which ranks are allocated. The costs of default might depend on the availability of formal savings alternatives (null for most individuals in our survey regions of Cotonou), the availability of other informal savings devices, the potential loss of reputation, or other sanctions imposed by groups on delinquent members (e.g. seizure of property, exclusion from other informal groups in the area). It is likely that the cost of default will be higher where groups are formed amongst those with stronger pre-existing social connections such as family. Thus, there is significant potential for ROSCAs to be designed in such a way that minimises the individual's incentive to default [11].

\subsection{Institutional Design}

A member's rank is one of the key parameters influencing sustainability in the model of Anderson et al. (2009). They illustrate that whilst a majority of members would prefer the ranks to be allocated according to a random draw, this will actually tend to increase the likelihood of experiencing enforcement problems. This result, however, relies on the assumption that ROSCAs are primarily used to save for the quick purchase of indivisible durable goods; receiving the pot earlier in the cycle allows the majority of individuals in the group to make the desired indivisible expense sooner than if they had saved alone (Besley et al., 1993). However, such assumption does not always hold. Gugerty (2007), using Kenyan data, and Dagnelie and LeMay-Boucher (2012), using the same sample as in this study, provide evidence that ROSCAs can be used as commitment devices. Instead of desiring an early place in the cycle, $60 \%$ of ROSCA members 
in our sample prefer later ranks in order to discipline themselves to save [12]. Fewer than one in four preferred to receive the pot at the beginning of a cycle. Given this, it is difficult to say whether fixed or random ROSCAs are likely to be more sustainable. However, as noted above, some fixed-order groups allocate ranks by attempting to accommodate their members' needs. Such groups might therefore be able to allocate ranks so as to minimise problems relating to payment. Specifically, a member facing financial difficulties, such as an unexpected income shock, might be allocated the pot at an earlier meeting. Similarly, members wishing for a late rank due to some commitment motive could be accommodated.

Conjecture 1: Given that a majority of individuals in our sample use ROSCAs as a commitment device, we do not expect the order of pot allocation (random/fixed) to play a significant role in the likelihood of experiencing enforcement problems. However, fixed order ROSCAs which accommodate their members' needs are expected to minimise the likelihood of problems occurring.

In our sample, ROSCAs are overseen by either a president or ruling committee of members. The costs of missing payments or defaulting can be significantly affected by how effectively the group is monitored or run and by how credibly those in charge reveal and enforce the threats of punishment to any potential delinquents. Paxton et al. (2000), for example, showed that a strong leader led to higher repayment rates of group loans in Burkina Faso.

Anecdotal field evidence from our pilot survey indicated that, given a set of similar group characteristics, president-led ROSCAs are generally more tightly run than those with a ruling committee. Presidents also appeared more involved in informally monitoring the activities of their members. This can be partly explained by the fact that a significant share of presidents are remunerated by the group for organising meetings and providing supervision; around half of 
presidents - compared to just one in ten committees - received remuneration for their role. The incentives for the rulers, who are also part of the ROSCA, to carry out their duties with greater diligence might be enhanced by the offer of remuneration. Handa and Kirton (1999) found that payments to the leader significantly increased the sustainability of ROSCAs. Furthermore, a number of presidents ( 8 out of 29) in our sample were founding members; this is less frequently the case for ruling committees. Founding members are often well-respected figures who can act with greater authority and are also more likely to have a keen understanding of the actions required to avoid and potentially solve problems.

Conjecture 2: Groups ( $i$ ) overseen by a president rather than a committee or (ii) where the rulers receive remuneration are expected to have a lower likelihood of experiencing enforcement problems.

The size of the pot of collective savings is another variable that could influence the incentives for a member to (cease to) make payments. Simply put, for a given membership size, a larger pot provides a greater temptation for a potential delinquent member to default (Besley et al., 1993).

Conjecture 3: A larger pot increases the incentive for any one member to cease contributing once (s)he has received it and hence leads to a higher likelihood of the group experiencing enforcement problems.

The frequency of meetings can also impact upon the likelihood that a group experiences enforcement problems. Besley et al. (1993) postulate that, holding membership size constant, increasing the duration of the ROSCA - as such implying less frequent meetings - can help to deter default. [13] Indeed, Handa and Kirton (1999) present some evidence to this effect; their study found that Jamaican ROSCAs meeting once per month were (albeit, only weakly 
significantly) less likely to experience problems than those meeting weekly. At the same time, it is conceivable that a group with less frequent meetings provides fewer opportunities for its members to meet together and strengthen their social connections, perhaps increasing the likelihood of default occurring.

Conjecture 4: For a given number of members, ROSCAs that meet less frequently are less likely to experience enforcement problems.

When the ROSCA has written rules, this might add a sense of formality to its functioning. If members have agreed to adhere to a set of rules outlining, for example, the sanctions against a defaulting member, then they might have a greater sense of their obligations to the group, thus lowering the likelihood that the group experiences problems. Wenner's (1995) study of 25 group credit programs in Costa Rica suggested that those with a 'written code' saw lower levels of delinquency, as did Zeller's (1998) study in Madagascar.

Conjecture 5: ROSCAs with written rules are less likely to experience enforcement problems.

The various sanctions faced by delinquent members were outlined in section 2 . To the extent that these present a meaningful punishment on potential delinquents, we would likely see a lower likelihood of a group experiencing enforcement problems, where more severe sanctions were in place.

Conjecture 6: In addition to the threat of social sanctions, those groups imposing other sanctions upon delinquent members will be less likely to see enforcement problems. 
Some ROSCAs allow new members at the start of a cycle and there will always be a degree of informational asymmetry with regards their reliability. It is therefore in the interests of the group to screen new entrants. The intuition is analogous to the work of Ghatak (1999), who showed that where group lenders were able to select new borrowers, they would potentially be able to achieve higher repayment rates. Often, restrictions are placed upon new members: ethnicity, gender, or trade. It stands to reason that where new members are more effectively screened, the group will be able to select those that are, ex ante, considered to be more reliable.

Conjecture 7: ROSCAs that screen new entrants are less likely to experience enforcement problems.

\subsection{Social Capital}

ROSCA members might incur fines or have their possessions seized if they miss payments, but of importance in this context is also the idea of social sanctions, arising from the social capital existing amongst members [14]. Putnam et al. (1993) argue that this can be viewed as a kind of collateral. Karlan (2007), for example, found evidence that strong social connections amongst group members lead to higher repayment rates in a group banking scheme in Peru.

As such, the fronting of so-called social collateral (Besley et al. 1993) helps overcome the problem of adverse selection by acting as both a screening device on new members and an enforcement mechanism amongst existing participants. The loss of reputation arising from nonpayment can be viewed as a 'social sanction'; such punishment becomes less desirable when higher levels of pre-existing social capital exist between members and it is conceivable that individuals would go to great lengths to avoid a bad reputation amongst family, friends, colleagues or business partners. The threat of losing one's social capital is therefore what could 
constitute much of the cost of default.

Whilst social capital may be pre-existing amongst members, it is also possible that it could accrue over time; trust and reciprocity can emerge as a result of repeated interactions, even between strangers. In ROSCAs, interactions between members are not only a result of financial motivations; groups often perform an important social function, e.g. meeting together for meals, or members doing business with one another. Such interactions can only serve to enhance cohesion amongst the group.

Conjecture 8: There is a lower likelihood that the ROSCA will experience enforcement problems: (i) where a higher level of social capital exists amongst members or (ii) with groups repeating interactions by completing more cycles.

\subsubsection{Monitoring and Peer Pressure}

Effective monitoring can lead to earlier and easier detection of problems, allowing the group to better deal with a member who is facing difficulties in making their payment. Monitoring is possible due to the social connectedness of group membership: where members interact outside the ROSCA setting (e.g. as part of the same business, neighbourhood or church), they are able to keep an eye on their peers. However, the ability of members to monitor each other is inherently dependent on numerous variables such as group design, size, or the frequency of meetings. Chiteji (2002) envisages that very large groups would involve monitoring costs outweighing the expected benefits from ROSCA participation. Besley et al. (1993) also postulated that default risk could be overcome by ex-ante reducing group size. 
Conjecture 9: Enforcement problems are more likely to occur in larger groups due to higher monitoring costs.

\section{EMPIRICAL STRATEGY AND RESULTS}

We use Probit analysis to estimate the following model:

$\operatorname{Pr}(\text { Enforcement Prob }=1)_{i, 04-06}=\alpha+\gamma \mathbf{X}_{i, 04}+\theta \mathbf{S}_{i, 04}+\varepsilon_{i, 04}$

where the dependent variable is a dummy variable equal to one if the ROSCA, $i$, experienced an enforcement problem between 2004 and 2006 [15]. X is a vector of characteristics related to the institutional design of the group, $\mathbf{S}$ is a vector of characteristics that proxy the level of social capital existing amongst members and $\varepsilon_{i}$ is the group-specific error term. All of the right-handside variables are measured in 2004 , meaning that we examine their effect on the likelihood of experiencing enforcement problems during the following two years. However, our survey lacks data for a number of variables capturing the composition of the group (i.e. individual characteristics of the members). These omitted variables may be linked to some of our independent variables as the membership is likely to the shape group's rules, structure and institutional design; this creates a potential problem of endogeneity. We thus acknowledge that the following results can only confidently be interpreted as correlations. Nevertheless, we think that, given the scarcity of results related to the topic of ROSCA sustainability and the richness of our data on ROSCA features and design, the estimations we present below can shed some valuable light. The results of the Probit estimations are shown in Table 2. Average Marginal Effects (AME) are shown.

\section{Conjecture 1}


Columns 1 and 2 consider the effects of the order of pot allocation on the likelihood of experiencing problems. 'Random' is a dummy variable taking the value 1 if this is decided according to a random process. 'Need' is a dummy equal to 1 if the allocation of the pot was done according to members' need for the money (discussed above). The reference category in column 1 is thus a group where the order of pot allocation was fixed according to some other criteria ('other fixed', discussed above). It is clear that those groups allocating the pot according to members' need were significantly less likely to have experienced enforcement problems than those allocating the pot to another criterion. The AME of around -0.5 suggests that groups allocating according to members' need were over 50\% less likely to have experienced enforcement problems compared to those that fixed according to some other process or randomly allocated the pot. There is no significant difference in the likelihood of enforcement problems between those allocating the pot randomly and any 'other fixed' process (column 2).

\section{Conjecture 2}

The variable 'President' is a dummy variable taking the value 1 if a single president oversees a group. Thus, the reference group is one overseen by a committee of members. 'President' is negative and statistically significant throughout the estimations presented. The magnitude of the AME suggests that groups overseen by a president were around a third less likely to experience enforcement problems compared to those overseen by a committee. These results are partially in line with those of Dagnelie (2008) who finds that a group with a president who is a founding member is less likely to experience a breakdown.

We also test the effect of groups remunerating their leaders. The variable 'paid' is a dummy equal to one if the ROSCA was led by a president or committee that was paid. When interacted with 'President' (Column 4), there is no evidence that those groups where a president was paid were 
significantly less likely to have experienced enforcement problems than those with an unpaid president.

\section{Conjecture 3}

The estimations present limited evidence that the size of the pot is related to the probability of enforcement problems occurring. Thus, we find no support for the predictions that a larger pot would increase the likelihood of default (Besley et al.,1993).

\section{Conjecture 4}

Included in all specifications is a variable 'Monthly Meetings', which is a dummy equal to one if the group met just once a month, the reference category being those groups meeting more regularly [16]. Across all specifications in table 2, it appears that those groups meeting monthly were indeed less likely to have experienced enforcement problems than those meeting more frequently. This result can also be explained by the fact that individuals facing unexpected shocks are more likely to find alternative sources of income to pay their contributions to the pot if they have a longer period of time to do so.

\section{Conjecture 5}

'Written Rules' is a dummy taking the value of 1 if groups had written rules. This variable is one of the most strongly related to the likelihood of having experienced enforcement problems. Across specifications, the AME is consistently around -0.2 and significant at the $1 \%$ level, suggesting that the likelihood of enforcement problems occurring in those groups with rules was around $20 \%$ lower, on average, than in those without.

\section{Conjecture 6}


The variable 'More Severe Sanctions', as defined in section 2 above, is a dummy equal to 1 for those groups imposing more severe sanctions on delinquent members. These sanctions are known by group members and in the vast majority of cases included in the written rules of a group. The results suggest that those groups threatening more severe sanctions on potential delinquents were around $25 \%$ less likely to have experienced enforcement problems on average. Due to the fact that these sanctions are, in the majority of cases, outlined in the written rules (where present), we exclude the rules variable in column 6 - the result remains unchanged. [17]

\section{Conjecture 7}

With regard to the screening roles performed by ROSCAS, there are a number of variables of interest, namely 'New members must be known', 'Survey on new members' and 'Other Conditions'. It would appear that the condition 'New members must be known' (where new members must be known to at least one current member) helps to minimise the probability of enforcement problems occurring. This condition might well be outlined in any written rules, but the result remains unchanged following the omission of the rules variable in column 6 . Taking groups where the entire membership decides as a reference, in column 5 we include a dummy variable taking the value of one when the president or committee makes the decision over whether to allow new entrants (denoted by the variable 'President/Committee decides'), however this is not statistically significant. Dagnelie (2008) also highlights the importance of screening for new members, finding that a variable similar to 'survey on new members' is significant in enhancing the survival probability of groups.

\section{Conjecture 8}

We next examine the pre-existing social connections between ROSCA members. Table 1 highlighted that groups in our sample are most frequently started amongst friends, but can also be formed with neighbours, family members of the same trade, church, or members of another 
group. We include dummy variables for $n-1$ of these categories, taking 'started with family' as the reference group, as such groups are likely to have the highest level of pre-existing social capital [18].

The positive and significant marginal effects on 'friends' and 'members of same trade' suggest that such ROSCAs were more likely to have experienced enforcement problems than those started with family. A group started amongst friends was 33-40\% more likely to experience enforcement problems than one started with family members. We find a similar result with groups started amongst members of the same trade and, to an extent, ROSCAs in the 'other' category. This result seems to suggest that where strong social ties exist, at least between the founding members of a group, there is a smaller likelihood of enforcement problems occurring. However, Bauchet and Larsen (2018) find that the type of relationship between members and their ROSCA leader did not have a significant role in the likelihood that it collapsed before completion of a cycle.

The variable 'Number of cycles completed' captures how many cycles each ROSCA had successfully completed before the 2004 survey. The results suggest that duration of existence has a role to play; the variable is always negative and significant at the $1 \%$ level: completing a further cycle might reduce the likelihood of enforcement problems occurring by around $2 \%$. This indicates that repeated interactions and completing more cycles can help to overcome the odds of experiencing enforcement problems. In section 5 below, we expand further on this.

The estimations also suggest that those groups that had experienced and survived problems before 2004 were more likely to see a recurrence; it appears common that a group which has experienced enforcement problems already will do so again, adding weight to the picture of instability and riskiness associated with investing one's savings in a ROSCA. 
We include further controls for groups whose membership was restricted to the same ethnicity or gender by including three dummies ('same ethnicity' 'only men' and 'only women'). We find that those purely composed of men (23 in our sample) seemed to have a lower likelihood of experiencing enforcement problems than mixed groups. Anecdotal evidence from several members of different groups indicated that mixed-gender groups can be more difficult to manage. According to some women interviewed, "men can often take too much space". Spouses in Benin have also been observed to be secretive about their incomes and have disconnected financial spheres (LeMay-Boucher and Dagnelie, 2014).

\section{Conjecture 9}

We see from table 2 that there is a negative relationship between membership size and enforcement problems; that is, in larger groups the likelihood of experiencing problems is actually lower. The magnitude of this impact is relatively small compared to others discussed above (i.e. written rules). This result might go some way to corroborating the argument that larger groups are better at dealing with a member who cannot make their payment, either because the contribution itself is relatively small, or purely because there are a higher number of others who could potentially step in to help or monitor. It can also be argued that peer pressure or monitoring exerted by each individual need not necessarily increase in larger groups. The mere fact that more people are aware of members' actions may be a sufficient deterrent against the threat of default. If ROSCAs meet together to make payments, which is the case for all groups in our sample, an individuals' reputation may take a much greater hit when it is announced to a larger number of people that he is unreliable. As such, the severity of social sanctions may be higher in a larger group.

\section{FURTHER DISCUSSION}




\subsection{Repeated interactions and sustainability}

The group surveyed for this study vary greatly in terms of their duration of existence: in the first survey wave, some had not completed their first cycle, whilst others had completed over 100 (average 8.5) [19]. Thus, it is possible that the 'young' groups are not quite comparable to the 'older' ones in terms of their functioning or interactions between members. In table 3, we present some robustness checks which investigate whether this is the case. Column 1 replicates the base specification from table 2, whilst in column 2, dummy variables are included for groups having completed different numbers of cycles at baseline $(<1,1-5,5-10$ and $>10)$. We see that, omitting groups which had completed over 10 cycles, (i) all the other groups were more likely to experience enforcement problems and (ii) the majority of results hold with a similar marginal effect. However, the monthly meetings variable is no longer statistically significant. In column 3, all of the 'young' groups are omitted from the regression, and we see that both the monthly meetings, more severe sanctions and started with friends variables lose their statistical significance. The results on need, president and written rules all remain, however. Finally, in column 4, where we exclude the 'old' groups, the original results all hold. These results suggest that, for the youngest of groups, certain institutional features are not as important as for older groups. For example, the result on more severe sanctions might reflect the fact that it is less likely that the younger groups will have experienced sanctions being threatened or employed on delinquent members, as the groups are still in their first cycle. [20]

In all previous results, the average marginal effects were shown. However, it is possible to compute marginal effects of covariates of interest at set levels of one of the other independent variables. Of particular interest is how the effects of some of the institutional features might change as ROSCAs get older. That is, as opposed to asking, "What is the average effect on the likelihood of enforcement problems of having a president (as opposed to a committee)?" we can 
ask, "What is the effect on the likelihood of enforcement problems of having a president (...) for a group that has completed X cycles?"

The plot in Figure 1 displays the marginal effects of three different institutional features on the probability of experiencing enforcement problems, measured at 5-cycle intervals. The features chosen are having written rules ('rules'), ruling structure ('president') and monthly meetings. These three features were selected as they were all (i) institutional design features that can be chosen by a ROSCA and (ii) significantly related to the likelihood of enforcement problems occurring in the Probit estimations above. We see that for 'young' groups, having a president is the least important institutional feature of the three for deterring enforcement problems. Key here, however, is that the importance of all three features declines as groups get older; this suggests a diminishing importance of institutional features over time, and support for the theory that repeated interactions amongst members can strengthen the bonds of trust and reciprocity within the group. It should be noted, though, that the $95 \%$ confidence intervals are quite wide here, likely due to the small sample size: the results should thus be viewed with this in mind.

Figure 2 plots the predictive margins of interaction terms between the three variables and as such allows us to examine those combinations of features that might be more or less likely to prevent to enforcement problems. It is clear that having a committee, no written rules and meeting more than once a month left groups most susceptible to problems; the marginal effects suggest that, at between 0 and 5 completed cycles, the probability of problems in these groups was around $70 \%$. However, again we see that groups facing this initial disadvantage can, to an extent, overcome it if they survive the early cycles. After having completed 20 cycles, the marginal effect suggests that these groups were $47 \%$ more likely to have experienced enforcement problems, representing an improvement in their chances of not doing so, compared to some other structure, of over a third. Of course, it is true that for all combinations of the aforementioned features, increasing the duration of the group decreases the likelihood of experiencing enforcement problems (all of the 
plots slope downwards). But at, say, 50 completed cycles, the importance of institutional features appears greatly reduced (as does the difference between having different combinations of features), with even those groups facing the greatest initial disadvantage able to enjoy much greater odds of not experiencing enforcement problems.

\section{CONCLUSION}

This study has sought to highlight the institutional design of Beninese ROSCAs that were more or less likely to have experienced enforcement problems and a number of interesting insights emerge. Again, our results should be interpreted as pairwise correlations due to the concerns surrounding endogeneity, highlighted above. This represents a limitation of our analysis and suggests that future research on ROSCA sustainability would benefit from detailed data on groups' membership. Furthermore, future research may wish to play closer attention to the role of sanctions in deterring, or punishing, defaulters. Nevertheless, the results presented herein provide some interesting empirical evidence in a space that has received scant attention in the literature. We observe that groups run by a president, those with written rules and those that fixed the allocation of the fund according to member's need were less likely to have experienced enforcement problems between 2004 and 2006. Our results do not find support for the theory which suggested that random allocation ROSCAs have suffer more enforcement problems than fixed ROSCAs. Furthermore, we find evidence that groups meeting less frequently, or those that were larger, were less likely to experience enforcement problems, corroborating some of the predictions in Besley et al. (1993). Our results also suggest that groups started with family members are less likely to have experienced problems compared to those started with friends or colleagues. This corroborates the notion that groups with stronger existing ties will be closer-knit and therefore less likely to experience enforcement problems (Karlan, 2007). An analysis of the importance of institutional design over time highlights that groups facing an initial disadvantage 
can, by successfully completing more and more cycles, lower their likelihood of facing default.

Repeated group interactions can help to reinforce group stability. 


\section{NOTES}

[1] ROSCAs have also been observed amongst ethnic minorities or immigrant groups in developed countries; see e.g. Bonnett (1981) or Summerfield (1995)

[2] For example, when Dupas et al. (2012) offered to remove the cost of opening a bank account for rural Kenyans, only $18 \%$ actively used the accounts whilst over $40 \%$ of their sample continued to use a ROSCA. Bouman (1995) refers to many African countries showing high participation rates, from 50 to 95\%. In Benin, (Author Reference: Omitted) find that around 20\% of individuals are members of a ROSCA.

[3] However, a shortcoming of Handa and Kirton (1999) is that their regressions are based on retrospective information, so any groups that have collapsed were, by implication, omitted from the study - we show below that often groups that have experienced problems collapsed (therefore the sample is biased toward those groups better equipped to deal with enforcement problems).

[4] More details about the survey methodology can be found in Appendix A.

[5] The sampling of this study was initially intended to examine the different characteristics explaining ROSCA membership at the individual level (Author Reference: omitted). Our sample was thus formed of randomly selected member and non-member individuals. The present study is a by-product of this fieldwork and so the sampling was not designed to primarily target and maximise the number of ROSCAs. Thus, we have a large number of households sampled compared to the number of ROSCAs. 
[6] However, there were no cases where the correct individual was located and (s)he refused to be surveyed again.

[7] This paper observes groups over time, without interference. We do not consider whether exogenously switching institutional characteristics has any impact on a given set of groups in the context of a field experiment. Such treatments, whilst potentially feasible, could also have important negative consequences on their sustainability and operations. Our preliminary fieldwork suggested that such experiments would either be difficult to implement or risky and as such not workable in this context.

[8] Anderson et al. (2009) refer to enforcement problems as a scenario where a member ceases to make payments before a cycle has been completed, or where a member receives an unfavourable rank and leaves the group before making any payments. Given the low occurrence of non-payments it was not possible to construct a count variable for the number of non-payments in a given ROSCA cycle. Alternatively, the number of excluded members is also a relatively rare occurrence and as such could not be used in our analysis. Only four groups (out of 97) have had to exclude members since the group started their activities (so over the entire life of the group and this can date back to many years before 2004).

[9] In the original survey in 2004, a number of groups listed that they excluded members for issues relating to non-payment. However, none of the groups surveyed again in 2006 - and thus included in the sample of 97 here - listed this as one of their sanctioning mechanisms.

[10] Common answers were that new members must 'have an income generating job' or simply 'have good morals'. 
[11] A plausible assumption often made in the ROSCA literature is that the same set of incentives will apply to all members and thus the group as a whole. One can justify this via the observation that members are often relatively homogenous individuals (e.g. employed in the same trade or coming from the same neighbourhood) who are able to commit to the same saving patterns over time.

[12] There is no significant difference, in terms of motivation for joining, between fixed and random groups in our sample.

[13] See pages 796 and 806 of Besley et al. (1993) for detailed derivations. In brief, the value of expected lifetime utility of all members in the model presented increases in both $c$ and $t$, consumption and duration respectively. Thus increasing every members' expected lifetime utility - which depends on their membership of the ROSCA - should help to deter default.

[14] Putnam et al. (1993:167) define social capital as “...features of social organisation such as trust, norms and networks that can improve the efficiency of society by facilitating coordinated actions."

[15] We also ran the analysis with the dependent variable equal to one for a group that collapsed due to enforcement problems (this was the case for 23 groups). The results were broadly similar. However, we prefer the dependent variable as defined here as it follows the relevant theoretical literature more closely.

[16] The breakdown for the frequency of meeting for all groups is as follows: monthly (36 groups); twice per month (8); every ten days (3); weekly (34); every 5 days (12); twice per week (2); every 2 days (1) and daily (1). 
[17] The results regarding sanctions remain unchanged when the variable is specified differently, whereby we restrict the 'more severe' sanctions to just those where property is seized, or a member is fined. Not shown, but available upon request.

[18] There is, of course, a well-known counter argument here that groups containing many members of the same family might see the sanctioning/enforcement mechanisms undermined due to a reluctance to punish each other. (See, e.g., Sharma and Zeller, 1997).

[19] The average cycle length is 13 months. The variable 'number of cycles completed' varies from less than 1 to over 130, (mean of 8.6).

[20] For this analysis, survival models are an alternative technique that could be used. However our survey did not ask the exact date at which problems occurred or the group disbanded - it asks only whether this happened during a two year period.

\section{On behalf of all authors, the corresponding author states that there is no conflict of}

\section{interest.}




\section{REFERENCES}

Anderson, S., Baland, J-M. and Moene, K.O. (2009): "Enforcement in informal savings groups", Journal of Development Economics, Vol. 90, pp. 14-23.

Besley, T., Coate, S. and Loury, G. (1993): "The economics of rotating savings and credit associations", American Economic Review, Vol. 83, pp. 792-810.

Bauchet, J. and Larsen, V. (2018): "ROSCA Composition and Repayment: Evidence from Taiwanese Bidding ROSCAs”, The Journal of Development Studies, Vol. 54, pp.1483-1495

Bouman, F. (1995): "Rotating and Accumulating Savings and Credit Associations: A Development Perspective”, World Development, XXIII, pp. 371-384.

Chiteji, N.S. (2002): "Promises Kept: Enforcement and the role of rotating savings and credit associations in an economy", Journal of International Development, Vol. 14, pp. 393-411.

Dagnelie, O. (2008) “Life and Death of Roscas: Leadership, Election and Screening”, mimeo CSIC.

Dagnelie, O. and LeMay-Boucher, P., (2012) 'Rosca participation in Benin: A commitment issue'. Oxford Bulletin of Economics and Statistics, Vol. 74(2), pp. 235-252.

Dupas, P., Green, S., Keats, A. and Robinson, J. (2012): “Challenges in Banking the Rural Poor: Evidence from Kenya’s Western Province”, NBER WORKING PAPER No. 17851 
Ghatak, M. (1999): “Group Lending, local information and peer selection”, Journal of Development Economics, Vol. 60, pp. 27-50

Gracia, M. (2000): “Apport de la Banque Ambulante aux Systèmes Financiers Décentralises et aux Opérateurs Economiques", Paper presented at the International Symposium on Microfinance and the Promotion of Micro- and Small Enterprises, 12-14 June 2000, Praia, Cape Verde.

Gugerty, M. K. (2007): "You can't save alone: Commitment in Rotating Savings and Credit Associations in Kenya", Economic Development and Cultural Change, Vol. 55(2), pp. 251-282

Handa, S. and Kirton, C. (1999): “The economics of rotating savings and credit associations evidence from the Jamaican 'Partner'”, Journal of Development Economics, Vol. 60, pp. 173194.

Helms, B., Deshpande, R., Pickens, M. \& Sado, N. (2005): "Benin: country-level savings assessment." CGAP Savings Initiative. Washington, DC: World Bank. <http://documents.worldbank.org/curated/en/2005/08/6726005/benin-country-level-savingsassessment $>$ Accessed 27/7/2016.

Karlan, D. (2007): “Social Connections and Group Banking”, Economic Journal, Vol. 117(517), Pp. F52-F84.

LeMay-Boucher, P., and Dagnelie, O., (2014) 'The Divorced Spheres of Beninese Spouses', Journal of International Development, Vol. 26(1) Pp. 46-58

Paxton, J., Graham, D., \& Thraen, C. (2000): "Modelling Group Loan Repayment Behavior: New Insights from Burkina Faso", Economic Development and Cultural Change, 48(3), Pp.639- 
Putnam, D.P., Leonardi, R., and Nanetti, R.Y. (1993): “Social Capital and Institutional Success”, in Making Democracy Work: Civic Traditions in Modern Italy, Chapter 6, Princeton, NJ: Princeton University Press, pp.163-185

Sharma, M., and Zeller, M. (1997): "Repayment Performance in Group - Based Credit Programs in Bangladesh: An Empirical Analysis” World Development, Vol. 25(10), Pp. 1731 - 1742

Wenner, M. (1995): “Group Credit: A Means to Improve Information Transfer and Loan Repayment Preference", The Journal of Development Studies, Vol. 32(2), Pp.263-281

Zeller, M. (1998): "Determinants of repayment performance in credit groups: The role of program design, intragroup risk pooling, and social cohesion”. Economic development and cultural change, 46(3), pp.599-6 
Table 1: Summary Statistics and test of equivalence of means between ROSCAs experiencing enforcement problems between 2004 and 2006 and those that did not

\begin{tabular}{|c|c|c|c|c|c|c|c|c|c|}
\hline \multirow{2}{*}{ Variable } & \multicolumn{4}{|c|}{ Full Sample } & \multicolumn{2}{|c|}{ No Problems } & \multicolumn{2}{|c|}{ Problems } & \multirow[t]{2}{*}{ Difference } \\
\hline & Mean & Std. Dev. & Min & $\operatorname{Max}$ & Mean & S.E. & Mean & S.E. & \\
\hline \multicolumn{10}{|l|}{ DEPENDENT VARIABLE } \\
\hline Experienced enforcement problems & 0.34 & 0.476 & 0 & 1 & & & & & \\
\hline \multicolumn{10}{|c|}{ INDEPENDENT VARIABLES: INSTITUTIONAL DESIGN } \\
\hline Membership size & 33.175 & 33.930 & 4 & 175 & 37.469 & 5.0239 & 24.849 & 2.238 & $12.620^{*}$ \\
\hline No. of cycles completed & 8.639 & 21.165 & 0.15 & 131 & 11.183 & 3.205 & 3.188 & 0.435 & $7.995^{*}$ \\
\hline Duration of existence (months) & 67.309 & 93.594 & 1 & 480 & 79.063 & 13.399 & 44.515 & 9.289 & $34.547^{*}$ \\
\hline Only President & 0.299 & 0.460 & 0 & 1 & 0.313 & 0.058 & 0.273 & 0.079 & 0.040 \\
\hline President/ committee paid & 0.227 & 0.421 & 0 & 1 & 0.266 & 0.056 & 0.152 & 0.063 & 0.114 \\
\hline Random & 0.680 & 0.469 & 0 & 1 & 0.703 & 0.058 & 0.636 & 0.085 & 0.067 \\
\hline Need & 0.134 & 0.342 & 0 & 1 & 0.172 & 0.048 & 0.061 & 0.042 & 0.111 \\
\hline Other Fixed & 0.186 & 0.391 & 0 & 1 & 0.125 & 0.042 & 0.303 & 0.081 & $0.082 * *$ \\
\hline Written Rules & 0.598 & 0.493 & 0 & 1 & 0.672 & 0.059 & 0.455 & 0.088 & $0.217 * *$ \\
\hline Monthly meetings & 0.371 & 0.486 & 0 & 1 & 0.391 & 0.062 & 0.333 & 0.083 & -0.057 \\
\hline Weekly meetings & 0.351 & 0.480 & 0 & 1 & 0.313 & 0.058 & 0.424 & 0.087 & 0.103 \\
\hline More severe sanctions on delinquent member & 0.536 & 0.501 & 0 & 1 & 0.875 & 0.042 & 0.727 & 0.079 & $0.148^{*}$ \\
\hline Pot size $(100,000$ 's of CFA) & 1.233 & 1.666 & 0.008 & 10 & 1.325 & 0.240 & 1.055 & 0.175 & 0.270 \\
\hline Single ethnicity & 0.237 & 0.428 & 0 & 1 & 0.219 & 0.052 & 0.273 & 0.079 & -0.054 \\
\hline Only men & 0.237 & 0.428 & 0 & 1 & 0.234 & 0.053 & 0.242 & 0.076 & -0.008 \\
\hline Only woman & 0.155 & 0.363 & 0 & 1 & 0.156 & 0.046 & 0.152 & 0.063 & 0.005 \\
\hline \multicolumn{10}{|l|}{ INDEPENDENT VARIABLES: SOCIAL CAPITAL } \\
\hline Survived Past Problems & 0.206 & 0.407 & 0 & 1 & 0.063 & 0.030 & 0.485 & 0.088 & $-0.422 * * *$ \\
\hline \multicolumn{10}{|l|}{ Started with } \\
\hline Friends & 0.433 & 0.498 & 0 & 1 & 0.344 & 0.060 & 0.606 & 0.086 & $-0.262 * *$ \\
\hline Family & 0.082 & 0.277 & 0 & 1 & 0.094 & 0.037 & 0.061 & 0.042 & 0.033 \\
\hline Members of same trade & 0.144 & 0.353 & 0 & 1 & 0.156 & 0.046 & 0.121 & 0.058 & 0.035 \\
\hline Neighbours & 0.186 & 0.391 & 0 & 1 & 0.203 & 0.051 & 0.152 & 0.063 & 0.052 \\
\hline Other & 0.144 & 0.353 & 0 & 1 & 0.188 & 0.049 & 0.061 & 0.042 & $0.127^{*}$ \\
\hline President/Committee decides & 0.650 & 0.480 & 0 & 1 & 0.641 & 0.061 & 0.667 & 0.083 & -0.026 \\
\hline New members must be known & 0.608 & 0.491 & 0 & 1 & 0.609 & 0.062 & 0.606 & 0.086 & 0.003 \\
\hline Survey on new members & 0.794 & 0.407 & 0 & 1 & 0.828 & 0.048 & 0.727 & 0.079 & 0.101 \\
\hline Known and Survey & 0.464 & 0.501 & 0 & 1 & 0.500 & 0.063 & 0.394 & 0.087 & 0.106 \\
\hline Other conditions & 0.784 & 0.414 & 0 & 1 & 0.766 & 0.053 & 0.818 & 0.068 & -0.053 \\
\hline$N=97$ & & & & & & 64 & $N=$ & 33 & \\
\hline
\end{tabular}

Note: $* \mathrm{p}<0.1 ; * * \mathrm{p}<0.05 ; * * * \mathrm{p}<0.001$. The results comparing means are from a two-sample t-test. 
Table 2: Probit estimation; Enforcement Problems

\begin{tabular}{|c|c|c|c|c|c|c|}
\hline & 1 & 2 & 3 & 4 & 5 & 6 \\
\hline Membership size & $\begin{array}{c}-0.011 * * * \\
(0.002)\end{array}$ & $\begin{array}{c}-0.011 * * * \\
(0.002)\end{array}$ & $\begin{array}{c}-0.012 * * * \\
(0.002)\end{array}$ & $\begin{array}{c}-0.012 * * * \\
(0.003)\end{array}$ & $\begin{array}{c}-0.010 * * * \\
(0.002)\end{array}$ & $\begin{array}{c}-0.012 * * * \\
(0.003)\end{array}$ \\
\hline \# of cycles completed & $\begin{array}{c}-0.014 * * * \\
(0.003)\end{array}$ & $\begin{array}{c}-0.011 * * * \\
(0.002)\end{array}$ & $\begin{array}{c}-0.015 * * * \\
(0.003)\end{array}$ & $\begin{array}{c}-0.014 * * * \\
(0.003)\end{array}$ & $\begin{array}{c}-0.014 * * * \\
(0.003)\end{array}$ & $\begin{array}{c}-0.017 * * * \\
(0.003)\end{array}$ \\
\hline Random & $\begin{array}{c}0.048 \\
(0.072)\end{array}$ & & $\begin{array}{c}0.036 \\
(0.077)\end{array}$ & $\begin{array}{c}0.032 \\
(0.078)\end{array}$ & $\begin{array}{c}0.046 \\
(0.069)\end{array}$ & $\begin{array}{l}-0.053 \\
(0.075)\end{array}$ \\
\hline Need & $\begin{array}{c}-0.529 * * * \\
(0.144)\end{array}$ & $\begin{array}{c}-0.576 * * * \\
(0.132)\end{array}$ & $\begin{array}{c}-0.578 * * * * \\
(0.167)\end{array}$ & $\begin{array}{c}-0.568 * * * \\
(0.173)\end{array}$ & $\begin{array}{c}-0.49 * * * \\
(0.141)\end{array}$ & $\begin{array}{c}-0.750 * * * \\
(0.160)\end{array}$ \\
\hline Other Fixed & & $\begin{array}{l}-0.048 \\
(0.072)\end{array}$ & & & & \\
\hline President & $\begin{array}{c}-0.329 * * * \\
(0.100)\end{array}$ & $\begin{array}{c}-0.329 * * * \\
(0.100)\end{array}$ & $\begin{array}{c}-0.305 * * * \\
(0.105)\end{array}$ & $\begin{array}{c}-0.305 * * * \\
(0.105)\end{array}$ & $\begin{array}{c}-0.322 * * * \\
(0.090)\end{array}$ & $\begin{array}{c}-0.282 * * * \\
(0.088)\end{array}$ \\
\hline Paid & & & $\begin{array}{c}-0.094 \\
(0.135)\end{array}$ & $\begin{array}{c}-0.044 \\
(0.135)\end{array}$ & & \\
\hline President*Paid & & & & $\begin{array}{l}-0.060 \\
(0.138)\end{array}$ & & \\
\hline Written Rules & $\begin{array}{c}-0.204 * * * \\
(0.075)\end{array}$ & $\begin{array}{c}-0.204 * * * \\
(0.075)\end{array}$ & $\begin{array}{c}-0.211 \text { **** } \\
(0.078)\end{array}$ & $\begin{array}{c}-0.215 * * * \\
(0.079)\end{array}$ & $\begin{array}{c}-0.205 * * * \\
(0.071)\end{array}$ & \\
\hline More Severe Sanctions & $\begin{array}{c}-0.260 * * * \\
(0.096)\end{array}$ & $\begin{array}{c}-0.260 * * * \\
(0.096)\end{array}$ & $\begin{array}{c}-0.273^{* *} \\
(0.102)\end{array}$ & $\begin{array}{c}-0.264 * * \\
(0.111)\end{array}$ & $\begin{array}{c}-0.253 * * * \\
(0.094)\end{array}$ & $\begin{array}{c}-0.296 * * * \\
(0.096)\end{array}$ \\
\hline Pot size (CFA 100,000's) & $\begin{array}{c}0.017 \\
(0.016)\end{array}$ & $\begin{array}{c}0.017 \\
(0.016)\end{array}$ & $\begin{array}{c}0.022 \\
(0.017)\end{array}$ & $\begin{array}{c}0.024 \\
(0.019)\end{array}$ & $\begin{array}{c}0.017 \\
(0.015)\end{array}$ & $\begin{array}{l}-0.011 \\
(0.018)\end{array}$ \\
\hline Monthly Meetings & $\begin{array}{c}-0.225 * * * \\
(0.071)\end{array}$ & $\begin{array}{c}-0.225 * * * \\
(0.071)\end{array}$ & $\begin{array}{c}-0.240 * * * \\
(0.073)\end{array}$ & $\begin{array}{c}-0.249 * * * \\
(0.080)\end{array}$ & $\begin{array}{c}-0.229 * * * \\
(0.071)\end{array}$ & $\begin{array}{c}-0.195 * * * \\
(0.066)\end{array}$ \\
\hline Survived Past Problems & $\begin{array}{c}0.940 * * * \\
(0.182)\end{array}$ & $\begin{array}{c}0.940 * * * \\
(0.182)\end{array}$ & $\begin{array}{c}1.047 * * * \\
(0.232)\end{array}$ & $\begin{array}{c}1.035^{* * *} * \\
(0.239)\end{array}$ & $\begin{array}{c}0.898 * * * \\
(0.173)\end{array}$ & $\begin{array}{c}1.118 * * * \\
(0.210)\end{array}$ \\
\hline Single Ethnicity & $\begin{array}{c}0.100 \\
(0.080)\end{array}$ & $\begin{array}{c}0.100 \\
(0.080)\end{array}$ & $\begin{array}{c}0.136 \\
(0.085)\end{array}$ & $\begin{array}{c}0.131 \\
(0.089)\end{array}$ & $\begin{array}{c}0.092 \\
(0.076)\end{array}$ & $\begin{array}{c}0.201 * * * \\
(0.075)\end{array}$ \\
\hline Only Men & $\begin{array}{c}-0.374 * * * \\
(0.104)\end{array}$ & $\begin{array}{c}-0.374 * * * \\
(0.104)\end{array}$ & $\begin{array}{c}-0.428 * * * \\
(0.119)\end{array}$ & $\begin{array}{c}-0.427 * * * \\
(0.121)\end{array}$ & $\begin{array}{c}-0.344 * * * \\
(0.096)\end{array}$ & $\begin{array}{c}-0.375 * * * \\
(0.100)\end{array}$ \\
\hline Only Women & $\begin{array}{c}-0.109 \\
(0.070)\end{array}$ & $\begin{array}{l}-0.109 \\
(0.070)\end{array}$ & $\begin{array}{c}-0.151 * \\
(0.080)\end{array}$ & $\begin{array}{c}-0.145 * \\
(0.086)\end{array}$ & $\begin{array}{c}-0.090 \\
(0.063)\end{array}$ & $\begin{array}{c}-0.135 * \\
(0.072)\end{array}$ \\
\hline Group Started Amongst... & & & & & & \\
\hline Friends & $\begin{array}{c}0.364 * * * \\
(0.120)\end{array}$ & $\begin{array}{c}0.364 * * * \\
(0.120)\end{array}$ & $\begin{array}{c}0.408 * * * \\
(0.128)\end{array}$ & $\begin{array}{c}0.403 * * * \\
(0.130)\end{array}$ & $\begin{array}{c}0.342 * * * \\
(0.103)\end{array}$ & $\begin{array}{c}0.445^{* * *} \\
(0.128)\end{array}$ \\
\hline Members of same trade & $\begin{array}{c}0.392^{* * *} * \\
(0.148)\end{array}$ & $\begin{array}{c}0.392 * * * \\
(0.148)\end{array}$ & $\begin{array}{c}0.470 * * * \\
(0.163)\end{array}$ & $\begin{array}{c}0.469 * * * \\
(0.165)\end{array}$ & $\begin{array}{c}0.369 * * * \\
(0.139)\end{array}$ & $\begin{array}{c}0.420 * * * \\
(0.150)\end{array}$ \\
\hline Neighbours & $\begin{array}{c}0.152 \\
(0.135)\end{array}$ & $\begin{array}{c}0.152 \\
(0.135)\end{array}$ & $\begin{array}{c}0.173 \\
(0.131)\end{array}$ & $\begin{array}{c}0.174 \\
(0.131)\end{array}$ & $\begin{array}{c}0.144 \\
(0.124)\end{array}$ & $\begin{array}{c}0.268 * * \\
(0.131)\end{array}$ \\
\hline Other & $\begin{array}{l}0.204^{*} \\
(0.107)\end{array}$ & $\begin{array}{l}0.204^{*} \\
(0.107)\end{array}$ & $\begin{array}{c}0.234 * * \\
(0.109)\end{array}$ & $\begin{array}{c}0.236 * * \\
(0.110)\end{array}$ & $\begin{array}{c}0.207 * * \\
(0.092)\end{array}$ & $\begin{array}{c}0.201 \\
(0.130)\end{array}$ \\
\hline President/Committee Decides & & & & & $\begin{array}{c}0.057 \\
(0.054)\end{array}$ & \\
\hline Survey on new members & $\begin{array}{c}0.031 \\
(0.075)\end{array}$ & $\begin{array}{l}0.314 \\
(0.75)\end{array}$ & $\begin{array}{c}0.042 \\
(0.096)\end{array}$ & $\begin{array}{c}0.042 \\
(0.096)\end{array}$ & $\begin{array}{c}0.035 \\
(0.074)\end{array}$ & $\begin{array}{c}0.050 \\
(0.082)\end{array}$ \\
\hline New members must be known & $\begin{array}{c}-0.151 * * \\
(0.067)\end{array}$ & $\begin{array}{c}-0.151 * * \\
(0.067)\end{array}$ & $\begin{array}{c}-0.184 * * \\
(0.082)\end{array}$ & $\begin{array}{c}-0.184 * * \\
(0.082)\end{array}$ & $\begin{array}{c}-0.128 * * \\
(0.064)\end{array}$ & $\begin{array}{c}-0.148 * * \\
(0.067)\end{array}$ \\
\hline Other Conditions & $\begin{array}{c}0.042 \\
(0.063)\end{array}$ & $\begin{array}{c}0.042 \\
(0.063)\end{array}$ & $\begin{array}{c}0.089 \\
(0.069)\end{array}$ & $\begin{array}{c}0.088 \\
(0.069)\end{array}$ & $\begin{array}{c}0.04 \\
(0.061)\end{array}$ & $\begin{array}{c}0.008 \\
(0.058)\end{array}$ \\
\hline $\begin{array}{l} \\
P \text { seudo- } R^{\prime}\end{array}$ & $\begin{array}{c}97 \\
0.63\end{array}$ & $\begin{array}{c}97 \\
0.63\end{array}$ & $\begin{array}{c}97 \\
0.67\end{array}$ & $\begin{array}{c}97 \\
0.67\end{array}$ & $\begin{array}{c}97 \\
0.67\end{array}$ & $\begin{array}{c}97 \\
0.63\end{array}$ \\
\hline
\end{tabular}

Dependent Variable $=1$ if ROSCA experienced enforcement problems between 2004 and 2006

$* p<0.1 ; * * p<0.05 ; * * * p<0.01$. Average marginal effects shown. Robust Standard errors in parentheses. 
Table 3: Robustness checks on number of cycles completed; Probit estimation.

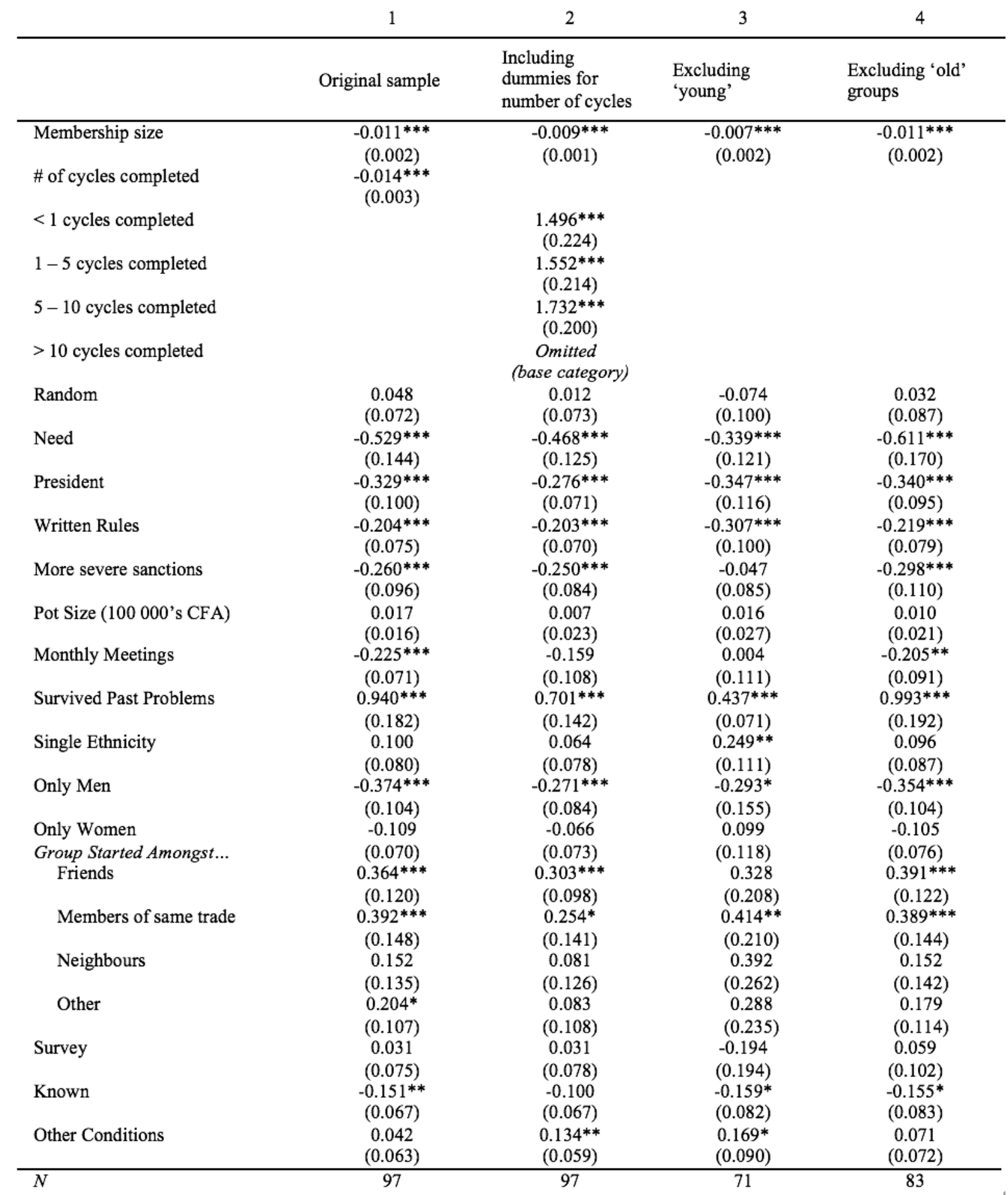

Dependent Variable $=1$ if ROSCA experienced enforcement problems between 2004 and 2006; * $\mathrm{p}<0.1$; ** $\mathrm{p}<0.05$; $* * * \mathrm{p}<0.01$. Average marginal effects shown. Robust Standard errors in parentheses. 'Young' refers to those groups that had completed less than 1 cycle at the time of the first survey wave in 2004, whilst 'old' groups are those that had completed more than 10. 
Figure 1. Marginal Effects of Institutional Features measured at different stages in the ROSCA life cycle

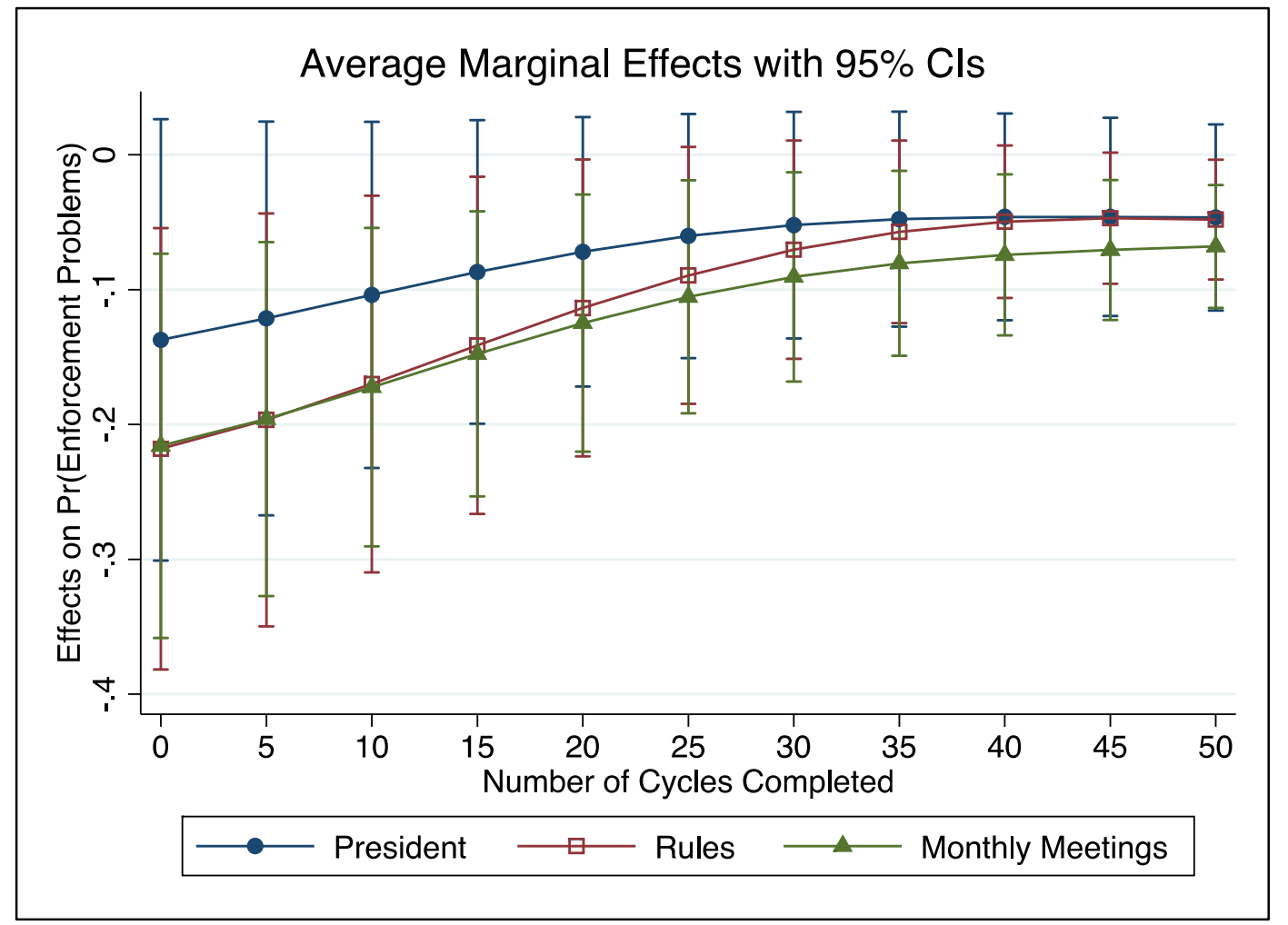

Figure 2. Marginal effects of interactions of Institutional Features measured at different stages in the ROSCA life cycle

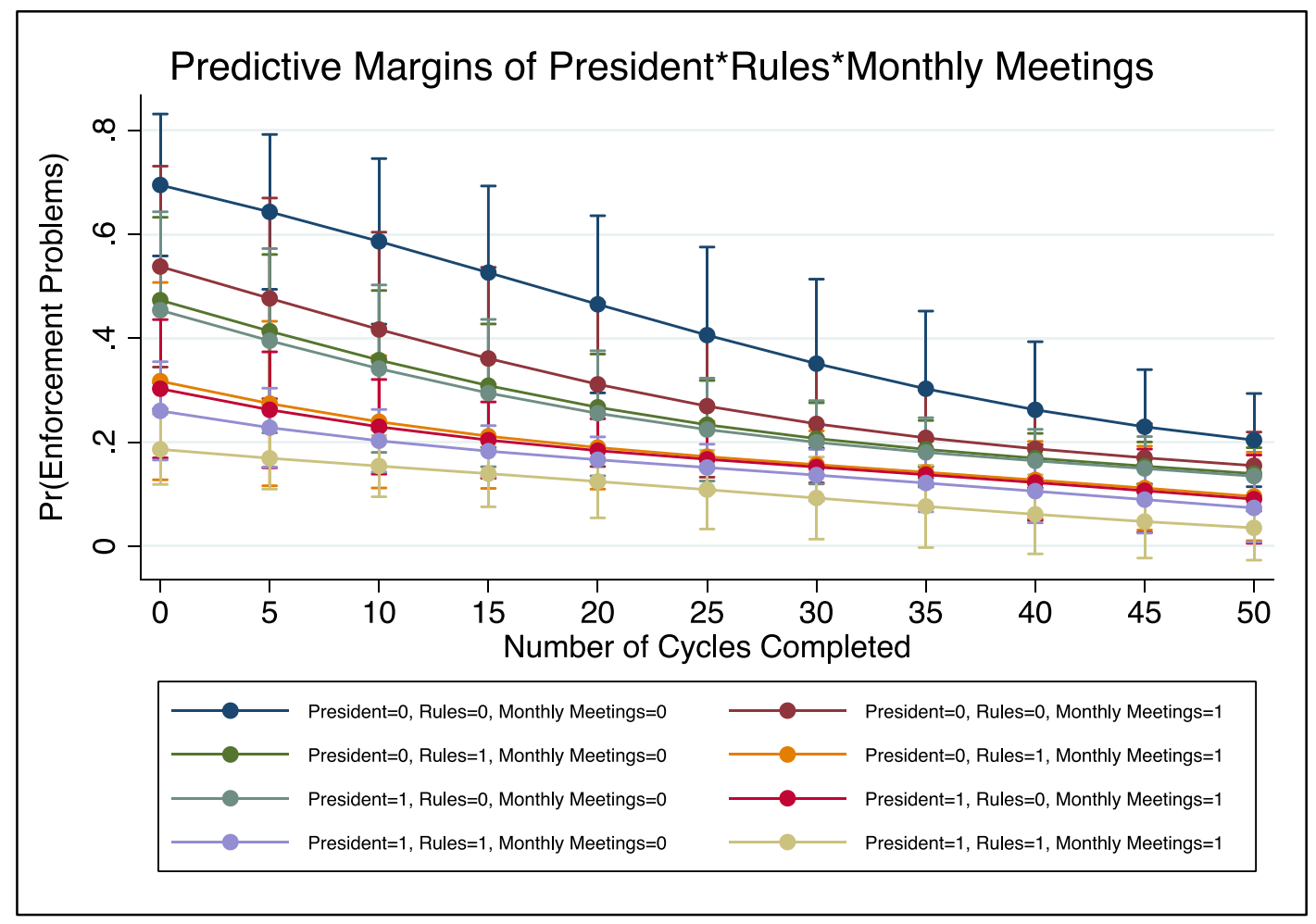


Appendix A. Survey Methodology

Our survey was carried out in two of the poorest areas of the city of Cotonou, namely Vossa and Enagnon. Households were selected according to the following process: After obtaining a map of Enagnon, we performed a simple random selection of lots out of all those identified. In Vossa we used a pseudo-random process, by which every tenth lot according to a specific direction was picked up. Starting points were selected to be equidistant from one another and so that they covered the whole district. In these two districts it is often the case that many households live on the same lot in semi-detached rooms. Enumerators selected one room per lot according to a clockwise selection, varying from lot to lot (for the first lot of the day they selected the first room clockwise, for the second one the second room clockwise and so on). Overall, only 3 households categorically refused to be surveyed and were replaced by other randomly selected households. Enumerators were asked to pass several times and at different times of the day, until contacts were established in such a way that none of the selected households were skipped. The most qualified of our enumerators also acted as a supervisor and visited many households already interviewed in order to check the accuracy of the responses. We compensated every household for their time by donating 1500 CFA francs (around 3 USD). 
Appendix B: Attrition Regression; Probit Estimation

\begin{tabular}{|c|c|}
\hline & 1 \\
\hline Membership Size & $\begin{array}{l}-0.002 \\
(0.003)\end{array}$ \\
\hline \# of cycles completed & $\begin{array}{c}0.002 \\
(0.003)\end{array}$ \\
\hline Random & $\begin{array}{c}0.167 \\
(0.096)\end{array}$ \\
\hline Need & $\begin{array}{c}0.038 \\
(0.117)\end{array}$ \\
\hline President & $\begin{array}{l}-0.107 \\
(0.112)\end{array}$ \\
\hline Paid & $\begin{array}{l}-0.020 \\
(0.076)\end{array}$ \\
\hline President*Paid & $\begin{array}{l}-0.062 \\
(0.131)\end{array}$ \\
\hline Written Rules & $\begin{array}{l}-0.141 \\
(0.091)\end{array}$ \\
\hline More Severe Sanctions & $\begin{array}{l}-0.029 \\
(0.104)\end{array}$ \\
\hline Pot size (CFA 100’000’s) & $\begin{array}{c}0.016 \\
(0.027)\end{array}$ \\
\hline Monthly Meetings & $\begin{array}{l}-0.095 \\
(0.091)\end{array}$ \\
\hline Survived Past Problems & $\begin{array}{c}0.140 \\
(0.099)\end{array}$ \\
\hline Single Ethnicity & $\begin{array}{c}0.025 \\
(0.099)\end{array}$ \\
\hline Only Men & $\begin{array}{l}-0.098 \\
(0.097)\end{array}$ \\
\hline Only Women & $\begin{array}{l}-0.118 \\
(0.113)\end{array}$ \\
\hline Group Started Amongst... & \\
\hline Friends & $\begin{array}{l}-0.079 \\
(0.152)\end{array}$ \\
\hline Members of same trade & $\begin{array}{l}-0.122 \\
(0.170)\end{array}$ \\
\hline Neighbours & $\begin{array}{l}-0.090 \\
(0.168)\end{array}$ \\
\hline Other & $\begin{array}{c}0.183 \\
(0.188)\end{array}$ \\
\hline Survey on new members & $\begin{array}{l}-0.084 \\
(0.107)\end{array}$ \\
\hline New members must be known & $\begin{array}{l}-0.018 \\
(0.088)\end{array}$ \\
\hline Other Conditions & $\begin{array}{c}0.000 \\
(0.104) \\
\end{array}$ \\
\hline $\begin{array}{l}N \\
\text { Pseudo- } R^{2}\end{array}$ & $\begin{array}{l}181 \\
0.09\end{array}$ \\
\hline
\end{tabular}

Dependent variable $=1$ if ROSCA was surveyed in both 2004 and 2006; One observation is dropped due to missing data. Average marginal effects shown; Robust standard errors in parentheses; *** $\mathrm{p}<0.01, * * \mathrm{p}<0.05$, * $\mathrm{p}<0.1$ 